\title{
TRABALHO CONCEITUAL EM PSICOLOGIA: PESQUISA OU "PERFUMARIA"?
}

A historiografia positivista da psicologia prega como um dos fatores responsáveis pela independência científica da disciplina psicológica o divórcio com a filosofia e o compromisso exclusivo com o método experimental. Outra versão é apresentada pela historiografia contemporânea da Psicologia: o pai da psicologia científica, Wilhelm Wundt (1832-1920), nunca preconizou essa separação, muito pelo contrário, advertiu que tal rompimento reduziria o psicólogo a um mero aplicador de técnicas. Mais do que isso, Wundt não defendeu um monismo metodológico pautado no método experimental, pois a "psicologia dos povos" requeria outros procedimentos e técnicas para o estudo dos fenômenos culturais (Araújo, 2010). Não obstante, já é sabido qual dessas versões tornou-se a história oficial e dominante da Psicologia.

A evidente predileção pela historiografia positivista da Psicologia ecoa na contemporaneidade. Uma de suas expressões é a ênfase na pesquisa factual em detrimento da pesquisa conceitual. $\mathrm{O}$ exemplo mais paradigmático dessa tendência é a ideia de que a expressão lídima da pesquisa científica é aquela pautada pelo método experimental, ou quase experimental. Essa tese foi criticada por outras tendências metodológicas, sob a alegação de que o método experimental não seria capaz de apreender a complexidade do fenômeno psicológico em suas diferentes expressões. A despeito da pertinência e correção dessa crítica, ela ainda não é suficiente para abalar o cerne da questão, pois, não raro, a discussão é deslocada para qual método é mais adequado para investigar o objeto da Psicologia. O privilégio do fato sobre a teoria permanece incólume; a ideia de que pesquisa é pesquisa factual, seja por que método for, subsiste com diferentes roupagens. Talvez seja o caso de atualizar este certeiro diagnóstico de Wittgenstein (1975): "existem na psicologia métodos experimentais e confusão conceitual" (p. 226), dizendo que na psicologia existem métodos (experimentais e não experimentais) e confusão conceitual.

Mesmo com a permanência de alguns clichês, tais como o de que a teoria é importante para a prática, há evidências informais e outras institucionalizadas que endossam o desequilíbrio epistêmico em prejuízo da pesquisa conceitual. Diz-se, por exemplo, que a pesquisa conceitual, a rigor, não é um tipo de pesquisa, pois não é orientada por um método. Outros, de modo mais jocoso, alegam que é superficial e subjetiva, uma vez que lida com a interpretação e não com a observação. Outros ainda reclamam que a "pesquisa" conceitual debate aquilo que já está consagrado e canonizado pela comunidade científica, como se fosse uma "pesquisa" que tratasse de truísmos. Ora, os fundamentos teóricos e epistemológicos da Psicologia já estão prontos, basta erigir o edifício científico sobre eles. Não abramos a "caixa preta" da história da constituição dos conceitos e fatos psicológicos. Não discutamos os compromissos filosóficos das teorias psicológicas, pois o tempo urge e precisamos resolver os problemas que batem à porta da Psicologia. Essas parecerem ser a lógica e recomendação vigentes.

Dificilmente alguém brada essas assertivas aos quatro ventos, mas basta uma olhadela nas propostas de mudança dos currículos de Psicologia para perceber que as disciplinas teóricas estão perdendo espaço para as de caráter mais técnico. Até mesmo as disciplinas de pesquisa, tão imprescindíveis a uma boa formação e atuação do psicólogo, geralmente apartam a discussão metodológica da teórica; ou não incluem a pesquisa conceitual ao lado de outras atividades que usualmente caracterizam o método científico, como a observação e o domínio de técnicas de obtenção e compilação de dados. É como se os procedimentos metodológicos pudessem transitar de modo independente das teorias que lhes dão sustentação, e sentido aos dados obtidos por meio deles. Basta conferir as programações dos congressos de psicologia para notar quais são as preocupações em voga.

As objeções à pesquisa conceitual também parecem ter ganhado apoio institucional. Nota-se uma restrição à publicação de artigos teóricos em periódicos bem avaliados. (Há exceções, como, por exemplo, esta revista, Psicologia em Estudo, que admite em sua política editorial a publicação de estudos teóricos, entendidos como resultado de pesquisa conceitual). Além disso, é difícil estabelecer linhas de pesquisa em programas de pósgraduação que privilegiem esse tipo de pesquisa. Os alunos que esboçam a vontade de trilhar essa vertente são geralmente desmotivados: há um número escasso de pesquisadores que orientam nessa área; os concursos públicos dificilmente destinam vagas para Fundamentos da Psicologia; os financiamentos para esse tipo de 
pesquisa são parcos, e assim por diante. Aqueles mais resilientes muitas vezes vão procurar guarida em programas de mestrado e doutorado em áreas afins, como na Filosofia, "maculando" o currículo de especialista em Psicologia. Esses e outros aspectos ajudam a entender a migração crescente de pesquisadores para a área da pesquisa factual, relegando a pesquisa conceitual a um "hobby acadêmico" ou a uma atividade que merece dedicação somente após uma consolidação institucional por parte do pesquisador.

Quais são as consequências desse desequilíbrio epistêmico? Esse assunto já foi debatido por diferentes autores (Abib, 2005; Machado, Lourenço, \& Silva, 2000; Tourinho, Carvalho Neto, \& Neno, 2004), mas vale recuperar aqui alguns pontos. Uma consequência consiste na proliferação de vulgatas e interpretações equivocadas sobre a obra dos principais teóricos da Psicologia. Isso se vê, por exemplo, em afirmações que identificam o comportamentalismo de Watson com o de Skinner; ou naquelas que consideram Piaget um reducionista biológico; ou mesmo nas que declaram que Wundt queria apartar a Psicologia da Filosofia.

A fragmentação e hiperespecialização do campo psicológico é outra consequência. Sem o papel heurístico e integrador da teoria, o pensamento analítico, que busca compreender o fenômeno divisando suas partes, dificilmente consegue fazer o caminho de volta, buscando a síntese. Descontextualizado do todo, o exame da parte isolada ganha autonomia e inaugura outro ramo de investigação psicológica, que passa a reclamar outros métodos e técnicas de estudo. E assim a Psicologia se fraciona à medida que se "descobrem" novas seções do fenômeno psicológico.

Outra infeliz consequência é o movimento pendular entre dogmatismo e ecletismo percorrido por alguns estudantes e profissionais de psicologia. De um lado, a falta de reflexão sobre os pressupostos filosóficos dos sistemas de Psicologia contribui para uma defesa obstinada de um desses sistemas. Nessa ótica, a diversidade teórica da Psicologia deveria ser impugnada em favor da teoria escolhida, que é conclamada como $a$ "verdadeira" teoria psicológica. O aluno é ensinado a ver a diversidade psicológica com desdém, o que é enriquecido com argumentos sobre o caráter pré-paradigmático da Psicologia. A busca por uma unificação ou teoria psicológica geral, como a "teoria de Tudo" na física, é almejada. O sonho de uma graduação exclusiva à teoria de interesse é nutrido, já que as demais vertentes são vistas apenas como obstáculo ao progresso do conhecimento psicológico. O aluno é disputado como epígono para fortalecer a barreira de proteção da teoria contra críticas internas e externas.

Em outro extremo, a diversidade da psicologia é celebrada com um ecletismo inconsequente. Aglutinam-se teorias incompatíveis do ponto de vista epistemológico. Afastam-se, por outro lado, teorias com afinidades eletivas, interditando o diálogo virtuoso entre elas. Somado a isso, a escolha da abordagem psicológica parece circunscrita ao problema local. Sem fazer justiça à complexidade das teorias, podemos imaginar o seguinte quadro: se a demanda é por uma solução rápida de problemas, usa-se a teoria comportamentalista, já que é "superficial, atendo-se apenas ao sintoma"; mas se o problema é mais "profundo", vale a pena recorrer à Psicanálise, ou, talvez, à psicologia fenomenológica. Se o problema é de aprendizagem, emprega-se um pouco da teoria piagetiana; se, além disso, a dificuldade demandar alguma análise social, uma "pitada" de teoria históricocultural parece ser uma boa medida; e, assim vai sendo cosida a colcha de retalhos da Psicologia.

$\mathrm{Na}$ contramão dessa tendência, defende-se, aqui, que a pesquisa conceitual é necessária ao progresso científico da Psicologia, e não um obstáculo a ele. A pesquisa conceitual consiste em um processo sistemático de investigação que visa produzir, ao final, conhecimento científico mediante o exame dos conceitos das teorias psicológicas. Esse estudo se dá, ao menos, em três níveis de análise. O primeiro situa o(s) conceito(s) na rede conceitual mais ampla da teoria psicológica em discussão; o segundo nível sonda os compromissos filosóficos (ontológicos, epistemológicos, éticos, estéticos) do(s) conceito(s) analisado(s); e o terceiro nível de análise examina o contexto histórico, social, biográfico, econômico e político da trama conceitual investigada.

Como em qualquer outro tipo de pesquisa, há uma pedra de toque para aferir as suas produções: são critérios sintáticos, semânticos, pragmáticos e práticos. Como qualquer outro tipo de pesquisa, exige preparo, estudo e dedicação. Como para qualquer outro tipo de pesquisa, ela é fundamental a formação e atuação do psicólogo. Por meio do exame da história e dos pressupostos filosóficos das teorias psicológicas, o psicólogo tem condições não só de discutir, mas também de produzir um conhecimento menos equivocado e mais afinado com os princípios basilares da teoria de interesse. Presumivelmente, também terá condições de lidar, de modo mais crítico e menos sacerdotal, com as teorias psicológicas, deixando de ser refém dos manuais, que, não raro, contribuem para perpetuar imprecisões teóricas. Sem eclipsar as virtudes, será capaz de reconhecer os limites da teoria escolhida e sondar possibilidades de superá-los. Com isso ele se afastará do dogmatismo. Conhecendo a história e os pressupostos filosóficos, o psicólogo terá condições de discernir relações de afinidade e influência entre diferentes 
teorias psicológicas. Ao situar as teorias em bases conceituais mais claras ser-lhe-á possível estabelecer um diálogo entre distintas abordagens. E, assim, ele se afastará do ecletismo.

Nessa perspectiva, a diversidade do campo psicológico não seria motivo de desalento. A meta deixa de ser a superação da diversidade para se tornar a superação do isolamento teórico. Que tal investir em uma conversa sem que isso incorra em ecletismo? Ao invés de incitar o aluno de graduação ou pós-graduação a criticar pejorativamente uma teoria psicológica desafeta, que tal instigá-lo a dialogar com ela orientado por uma reflexão conceitual? Não seria uma ocasião propícia para cultivar o tão apregoado - e necessário - respeito pela diferença?

A ideia, aqui, não é fomentar outro desequilíbrio: privilegiar a pesquisa conceitual em detrimento da factual. Trata-se tão somente de advogar a favor da busca por uma relação nivelada entre esses tipos de pesquisa. Isso reclama um esforço conjunto no âmbito da graduação e da pós-graduação; exige também reflexões por parte da comunidade científica com respeito às suas práticas de pesquisa, incluindo-se aí questões que vão desde o financiamento até o delineamento do perfil da política editorial de seus periódicos científicos e de normas de divulgação e publicação de trabalhos em outros meios especializados.

Ao que tudo indica, a busca por uma relação mais equilibrada entre pesquisa factual e pesquisa conceitual deixou de ser um compromisso estritamente epistemológico para se tornar também um compromisso ético com a formação e a atuação (profissional e acadêmica) do psicólogo.

Carolina Laurenti

Editora de Seção

e-mail: laurenticarol@gmail.com

\section{REFERÊNCIAS}

Abib, J. A. D. (2005). Prólogo à história da psicologia. Psicologia: Teoria e Pesquisa, 21(1), 53-60.

Araújo, S. F. (2010). O projeto de uma psicologia científica em Wilhelm Wundt: Uma nova interpretação. Juiz de Fora: Editora UFJF.

Machado, A., Lourenço, O., \& Silva, F. J. (2000). Facts, concepts, and theories: the shape of psychology's epistemic triangle. Behavior and Philosophy, 28, 1- 40.

Tourinho, E. Z., Carvalho Neto, M. B., \& Neno, S. (2004). A psicologia como campo de conhecimento e como profissão de ajuda. Estudos de Psicologia, 9(1), 17-127.

Wittgenstein, L. (1975). Investigações filosóficas (J. C. Bruni, trad.). In V. Civita (Ed.), Os pensadores (pp. 11-226). São Paulo: Abril Cultural. (Trabalho original publicado em 1953). 